\title{
Population structure and habitat use of baboons (Papio hamadryas ursinus) in the Blyde Canyon Nature Reserve
}

\author{
A.J. Marais, L.R. Brown, L. Barrett and S.P. Henzi
}

Marais, A.J., L.R. Brown, L. Barrett and S.P. Henzi. 2006. Population structure and habitat use of baboons (Papio hamadryas ursinus) in the Blyde Canyon Nature Reserve. Koedoe 49(2): 67-76. Pretoria. ISSN 0075-6458.

Baboons are highly intelligent and ecologically flexible animals with attributes that allow them to exploit diverse habitats. As a result of their dietary flexibility they often exploit human habitats, causing damage to crops and forest plantations as well as to human dwellings. In the South African context this has led to baboons being regarded as problem animals and attempted extirpation is the most common approach to the damage they cause. This perception of and attitude toward baboons gives many conservationists cause for concern since all southern African cercopithecine primates are CITES listed and it has not been proven that this strategy is the best long-term solution. As part of a research programme focusing on the damage done by chacma baboons in pine plantations along the Drakensberg escarpment in Mpumalanga, a single troop in the Blyde Canyon Nature Reserve was studied to describe their patterns of habitat use. Vegetation and habitat surveys were conducted within the home range of the troop. The troop was habituated and each member's activity, location and food items utilised were recorded over a 12 month period. The results of this study indicate that baboons utilised plant communities based on food production and availability rather than size in hectares. The results also indicate that the group size, foraging and food search strategies of this troop resembles that of the Drakensberg troops previously studied. The study troop employs two different forage modes of engagement depending on where they choose to forage while they avoid utilising an easily accessible pine plantation. Due to the troop's long inter-birth intervals it is likely that the current forestry practice of extirpation may have a negative influence on baboon population viability in these areas.

Key words: Chacma baboons, Mpumalanga, home range, population structure, habitat use.

\begin{abstract}
A.J. Marais and L.R. Brown $\varangle$, Applied Behavioural Ecology and Ecosystem Research Unit, University of South Africa; Private Bag X6, Florida, 1710 Republic of South Africa; L. Barrett and S.P. Henzi, Applied Behavioural Ecology and Ecosystem Research Unit, University of South Africa, (Present address: Department of Psychology, University of Central Lancashire).
\end{abstract}

\section{Introduction}

One corollary of the preservation of natural habitats is an increased probability of conflict between conservation objectives and other land-use practises in the vicinity. While the exact nature and extent of this conflict will obviously be locally determined (Hill 2000), it stems ultimately from the fact that conservation areas are designed to serve as reservoirs for both flora and fauna. In the
South African context, primates are regarded as particularly problematic residents of protected areas, as conventional fences do not readily enclose them, their eclectic diets allow them to benefit from a range of agricultural endeavours, and they are behaviourally opportunistic (Von dem Bussche \& Van der Zee 1985; Cowlishaw \& Dunbar 2000).

Where their depredations are not tolerated, attempted extirpation is the most common 


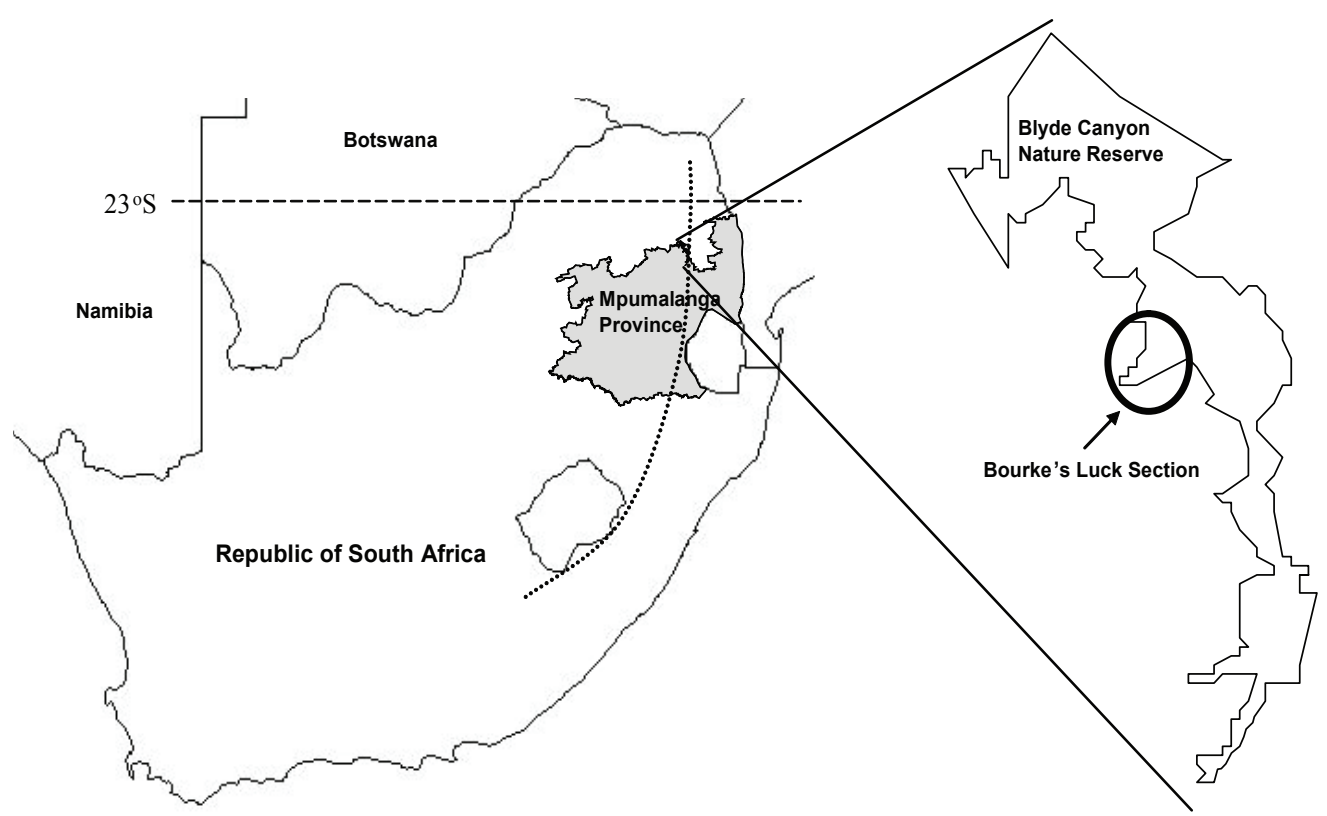

Fig. 1. A map of the study site's location within South Africa and Mpumalanga Province (shaded). The dotted line indicates the approximate location of the Drakensberg escarpment.

approach to the damage they cause. This is problematic for three reasons. First, all southern African cercopithecine primates are CITES listed (Appendix II). Second, there is as yet little evidence, in the absence of complete and permanent removal, that hunting and trapping are the most cost-effective strategies in the medium to long term. Third, there is little understanding of its effect on the refugial populations themselves. It is possible that control measures compensate for the reduction in predator numbers often associated with conservation islands (Cowlishaw \& Dunbar 2000), thereby allowing surrounding areas to serve as demographic sinks. It is, however, at least equally likely that such populations are not sustainable and, where this is so, the integrity of the refugium is threatened. Any effective policy for both conservation and problem animal control must address these issues and doing so clearly requires an enumeration of the extent of the problems.

Our own research focuses on the damage done by chacma baboons in pine (Pinus spp.) plantations along the Drakensberg escarpment in Mpumalanga province, South Africa. Advantages of rainfall and climate in this area have led to very large commercial plantings, while the escarpment itself and, especially, nature reserves in the area harbour baboon populations that generally have easy access to plantations. Baboons strip the bark of pine trees, thereby disrupting growth and preventing trees from being harvested (Bigalke \& Van Hensbergen 1990). They have the potential to make large inroads into the profitability of plantations, which in turn has consequences for local conservation policies.

Estimating costs accurately, and determining viable solutions, however, which is our overall objective, must begin with an understanding of the natural structure and ecology of the baboon populations involved. This is necessitated both by the need to predict the effects of control measures as well as the observation that not all trees are damaged and not all baboon troops that enter plantations 
are destructive in this way. Our aims in this paper, accordingly, are to outline the structure and density of the baboon population in the Blyde Canyon Nature Reserve (BCNR) and to describe the patterns of habitat use of one representative, habituated troop. The reserve has commercial plantations on its boundary and the troop was chosen because it had, potentially, easy access to these plantations.

\section{Study area}

Blyde Canyon Nature Reserve is a $280 \mathrm{~km}^{2}$ provincial reserve in Mpumalanga Province running along the escarpment that divides the South African highveld from the lowveld (Fig. 1). The vegetation is primarily a mixture of Mountain Sourveld (Acocks veld type 8) and Mixed Bushveld (Acocks veld type 18) (Acocks 1988) and as North-eastern Mountain Grassland (type 43) by Bredenkamp et al. (1996) which reflects the rugged topography and altitudinal gradient $(600 \mathrm{~m}-$ $2000 \mathrm{~m}$ asl). It is distinctive in containing populations of all five non-human primates that occur in southern Africa as well as their most important predators (python, crowned eagle and, especially important for baboons, the leopard).

The climate along the escarpment is mild. The mean temperature of the hottest months (January; February) is $21.3{ }^{\circ} \mathrm{C}$, while that of the coldest month (June) is $11.2^{\circ} \mathrm{C}$ (Fig. 2). Absolute temperatures vary between a maximum of $34.1^{\circ} \mathrm{C}$ (February) to $-2{ }^{\circ} \mathrm{C}$ (June). The months of May, June, July and August are normally the coldest months with early morning temperatures ranging between $-2{ }^{\circ} \mathrm{C}$ to $2{ }^{\circ} \mathrm{C}$ but increasing in midday to between $26.8^{\circ} \mathrm{C}$ and $28^{\circ} \mathrm{C}$. During the warmer months (December, January, February, March) the temperatures vary between $8.6^{\circ} \mathrm{C}$ and $14^{\circ} \mathrm{C}$ in the morning and $30.2^{\circ} \mathrm{C}$ and $34.1^{\circ} \mathrm{C}$ in the middle of the day.

Rainfall is the primary driving force influencing the productivity of vegetation and therefore food available to animals. Mean annual rainfall for the study area is $848 \mathrm{~mm}$, with most precipitation occurring in the austral spring and summer (Marais 2005). We used

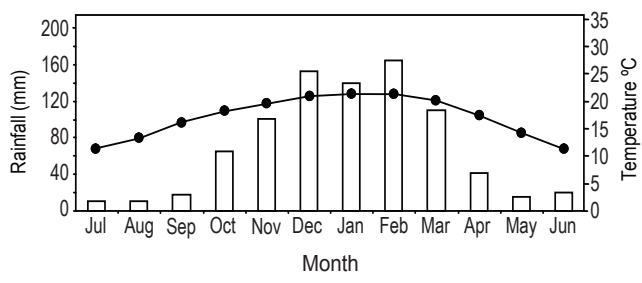

Fig. 2. Climate of the study area.

these data to divide the year into a wet (October-April) and dry season (May-September) for analysis. Mild mist would normally only be encountered during the raining season, but is restricted to the canyon sections only.

\section{Methods}

\section{Vegetation description and mapping.}

The vegetation of the home range of the troop was stratified into physiognomicphysiographic units using 1:20000 stereo aerial photographs. To ensure that all variations in the vegetation were considered and sampled, a total of 61 sample plots (200 $\mathrm{m}^{2}$ ) were located on a randomly stratified basis within the different units (Bredenkamp 1982; Bezuidenhout 1993). Vegetation and habitat surveys were conducted in each of the sample plots by recording all plant species present. The cover of the tree, shrub and herbaceous layers was estimated using the Braun-Blanquet cover abundance scale (Mueller-Dombois \& Ellenberg 1974).

\section{Population survey}

The baboon population of the BCNR was surveyed during bi-monthly walks along pre-determined routes. When troops were seen, they were counted and their location marked on a 1:50000 topographical map. Once the troops had been identified in this way, repeated sightings enabled confirmation of size and the estimation of home range size by the fitting of minimum convex polygons 


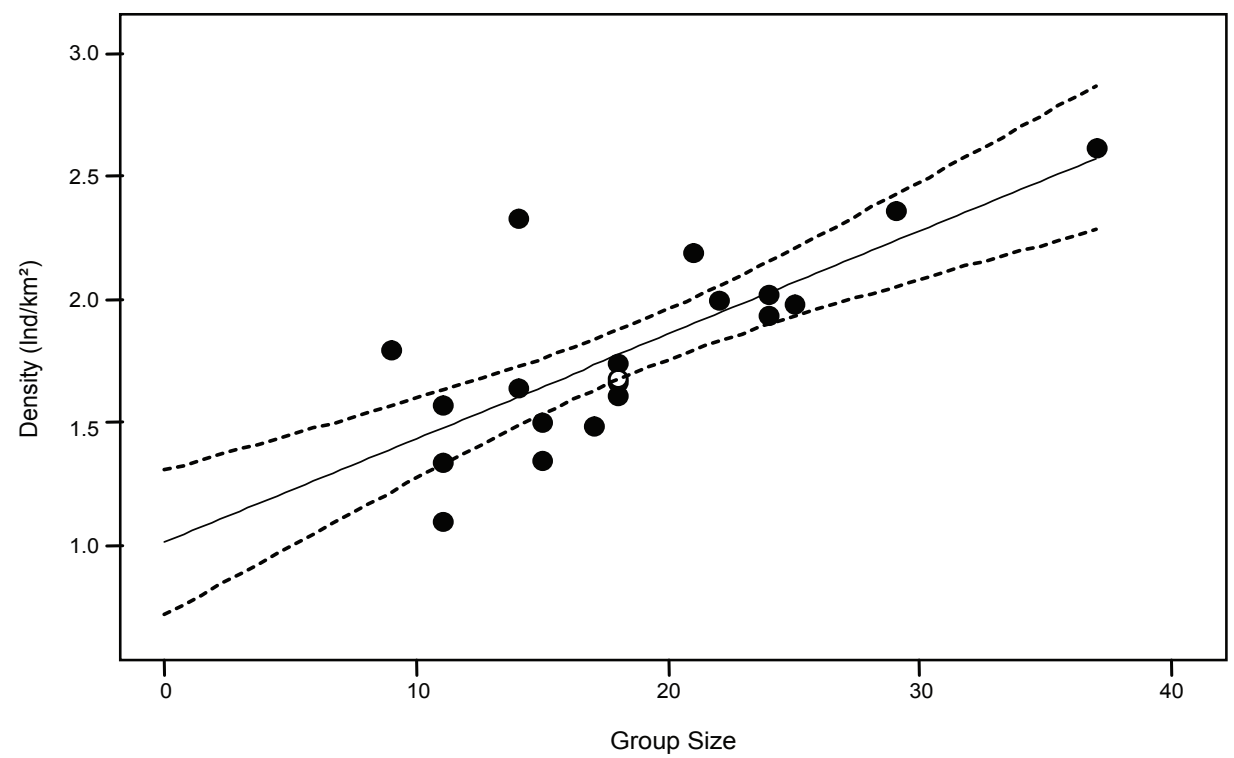

Fig. 3. The relationship between group size and population density. The best-fit regression line (Density $=0.042$ Size +0.756$)$ is provided together with its $95 \%$ confidence limits (dashed lines). The study troop is indicated by an open circle.

to the sightings of each troop using commercial GIS software (ArcInfo). Each troop was allocated to one of four visually identifiable habitat types (grassland, wetland/grassland, protea grassland and mixed bushveld) within the broad Acocks categories.

\section{Study troop habituation}

The study troop at Bourke's Luck $(n=18)$ was chosen because it was close to average size (see below) and because its home range extended at least to the reserve boundary. The troop was habituated by following it on foot until it could be observed at a distance of $30 \mathrm{~m}$. During habituation, data were collected on diet. Once it was habituated we recorded activity and location (as well as food items) over a 12-month period from June 2001 to May 2002.

\section{Data collection}

Activity budgets were determined through 15-minute scan samples of all visible group members. The age and sex of each animal was recorded together with its state (moving, resting, foraging, socialising). Data were collected using a hand-held data logger (Handspring) and commercial software (Pendragon Forms). During all-day follows, the location of the troop was recorded using a GPS logger whenever the estimated centre of mass shifted by more than $20 \mathrm{~m}$. These data were downloaded into a commercial GIS package and linked to a fine-grained habitat map of the home range. This allowed us to identify the habitat type occupied by the troop at each point sample. Home range area was estimated by fitting a minimum convex polygon to the points. Day range and habitat use information comes from 25 complete day ranges.

\section{Data analysis}

Data were downloaded from the data logger into a commercial spreadsheet package and exported to SPSS for analysis. We used the Shapiro-Wilk test to determine the normality of the data and found no significant devia- 
tions from the normal distribution. All tests were two-tailed with alpha set at 0.05 . The floristic data was analysed according to BraunBlanquet procedures using TURBOVEG (Hennekens 1996). By applying the Two-way indicator species analysis (TWINSPAN) (Hill 1979) to the floristic data, a first approximation of the main plant communities was derived. Further refinement of the classification was achieved by Braun-Blanquet procedures (Bredenkamp et al. 1989; Kooij et al. 1990; Bezuidenhout 1993; Eckhardt 1993; Brown \& Bredenkamp 1994).

\section{Results}

Population structure and density. Twentyone troops were counted, ranging in size from 9-37 animals. The mean troop size was 18.3 animals ( $\pm 6.8 \mathrm{SD})$. Troop size did not differ with recorded habitat type $\left(F_{3,17}=1.35\right.$; NS). One small troop, using a tourist residential zone, had a home range area that was significantly smaller than expected for its size (centred leverage value $>0.5$ ) and was excluded from the following analyses. The mean estimated home range area was $10.2 \mathrm{~km}^{2}$ ( $\pm 2.3 \mathrm{SD})$. There was a significant positive correlation between troop size and estimated home range area $(r=0.81 ; n=20 ; p<0.01)$. Density was calculated as home range area/ group size. The mean estimated population density was 1.8 baboons $/ \mathrm{km}^{2}$ ( $\left.\pm 0.4 \mathrm{SD}\right)$. This was also positively correlated with group size $(r=0.76 ; n=20, p<0.01)$ (Fig. 3).

Day-journey length. The average annual day-journey length for the Bourke's Luck troop during the study period was $3.37 \mathrm{~km}$ $( \pm 0.73 \mathrm{SD} ; n=25)$. The mean daily dry season distance was $3.78 \mathrm{~km}( \pm 0.74 \mathrm{SD} ; n=12)$, while the mean wet season distance was $2.99 \mathrm{~km}( \pm 0.48 \mathrm{SD} ; n=13)$. This difference in seasonal day journey length was significant $\left(t_{23}=3.16 ; p<0.01\right)$.

Day and home range size. The baboons utilised, on average, 34.47 ha per observation day ( $\pm 20.31 \mathrm{SD})$, resulting in a recorded annual home range size of $10.35 \mathrm{~km}^{2}$ (Fig. 4 - home range and day ranges). The mean day range area for the wet season was 31.44 ha $(n=13 \pm 10.56 \mathrm{SD})$ while that for the dry season was 52.3 ha $(n=12 \pm 23.0)$. This seasonal difference was significant $\left(t_{23}=2.95\right.$; $p<0.01)$. There was, overall, a positive correlation between day journey length and day journey area $(r=0.69 ; n=25 ; p<0.01)$.

Home range overlap. Two other baboon troops $\left(n_{1}=18 ; n_{2}=25\right)$ overlapped with the Bourke's Luck troop. The percentage overlap for both troops combined was relatively small at $7.5 \%$.

Habitat use. Topographically, the troop's home range varied from gentle to relatively moderate slopes of $2-6^{\circ}$ on the higher lying areas to valley bottoms where slopes were as steep as $60^{\circ}$. The habitat covered by the study troop's home range comprises six major plant communities, some with recognisable sub-communities or variants, generating a total of 12 distinctive floristic zones (Fig. 4) (Marais 2005).

The first point to note from Fig. 4 is that despite the presence of a large pine plantation the troop chose not to enter it; in fact, they went right up to it on at least two occasions and then turned away. Given this, we calculated the proportion of the annual home range contributed by each of the remaining plant communities (Fig. 4) and used the Electivity Index (EI) (Krebs 1989) to determine whether the study troop occupied plant communities only in relation to their availability or whether some were preferred and others avoided. The EI describes habitat as a score between -1 and +1 , where 0 indicates that a community is used in accordance with its availability, while plus and minus signs signal that communities are favoured or avoided respectively.

The data show, overall, that the baboons had distinct preferences for certain plant communities and avoided others (Fig. 5). In particular, there was a very high preference for the Englerophytum magalismontanumAcacia ataxacantha Woodland (community 6.1), which is the smallest plant community present at Bourke's Luck, covering an area of only 9.3 ha (1.8\% of the home range). The baboons also showed a preference for 


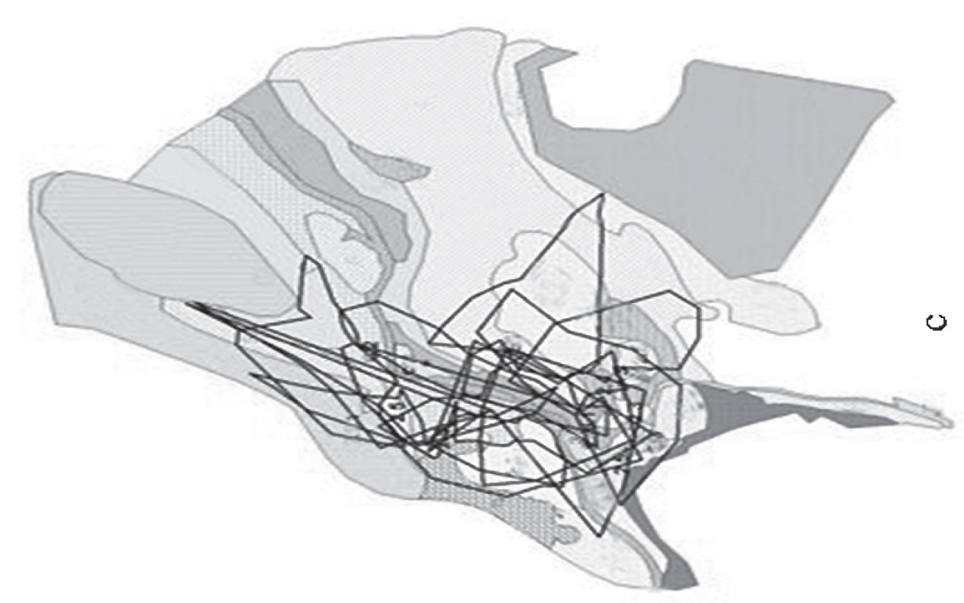

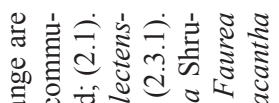

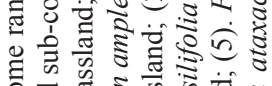

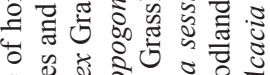

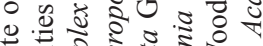

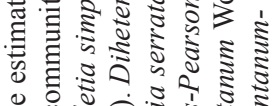

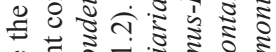

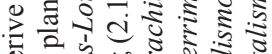

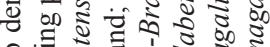

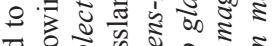

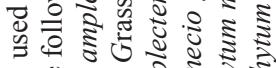
क्ष 푼?

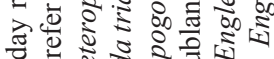

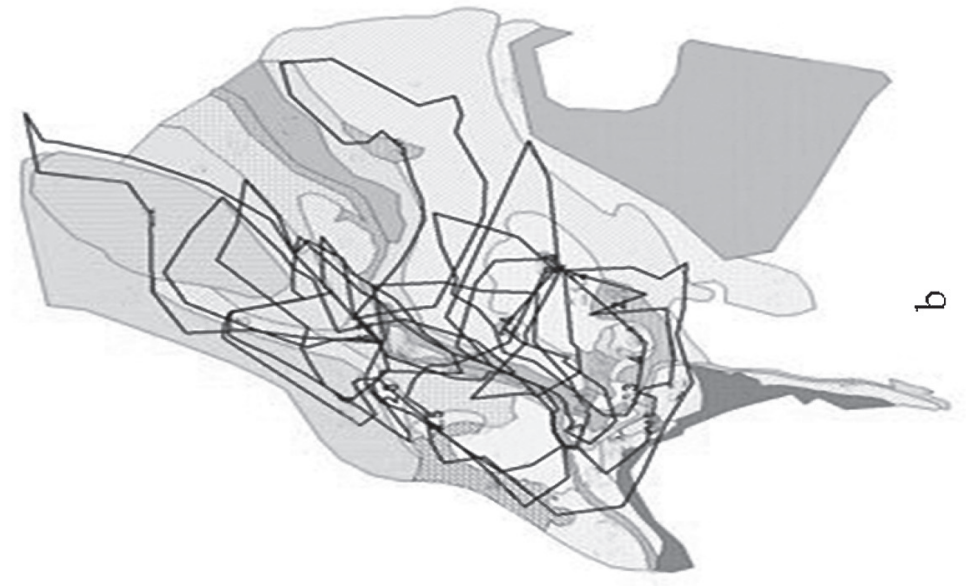

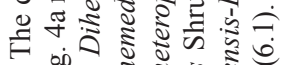
बंग

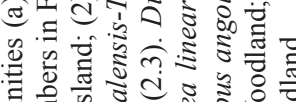

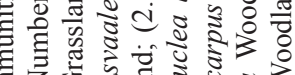

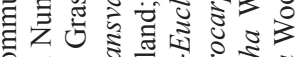

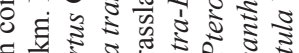
들

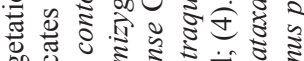

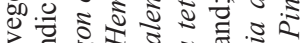

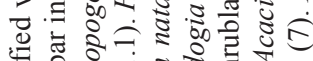

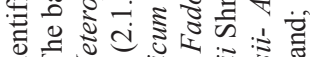

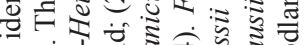
ป

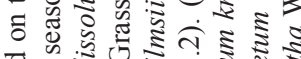
ซึ่

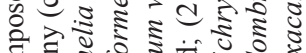

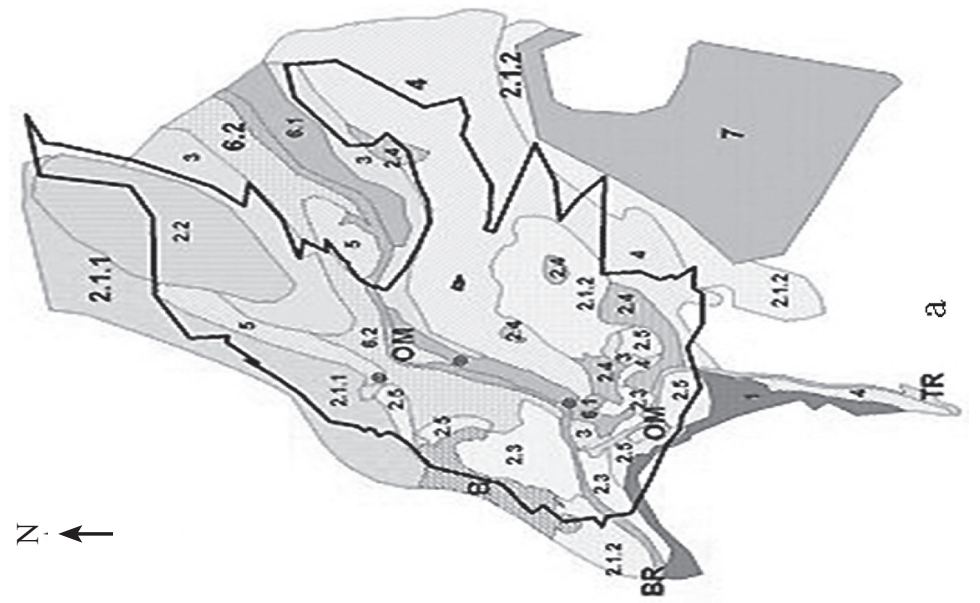

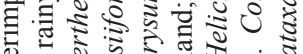

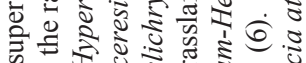
की อ

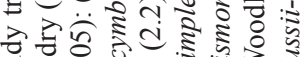
फ

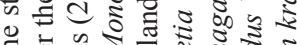
‡.

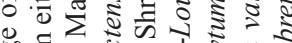

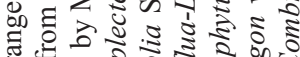

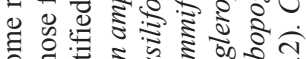

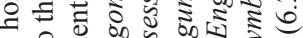

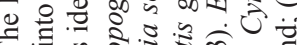

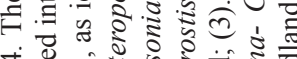

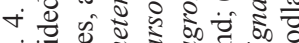

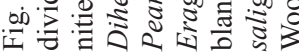



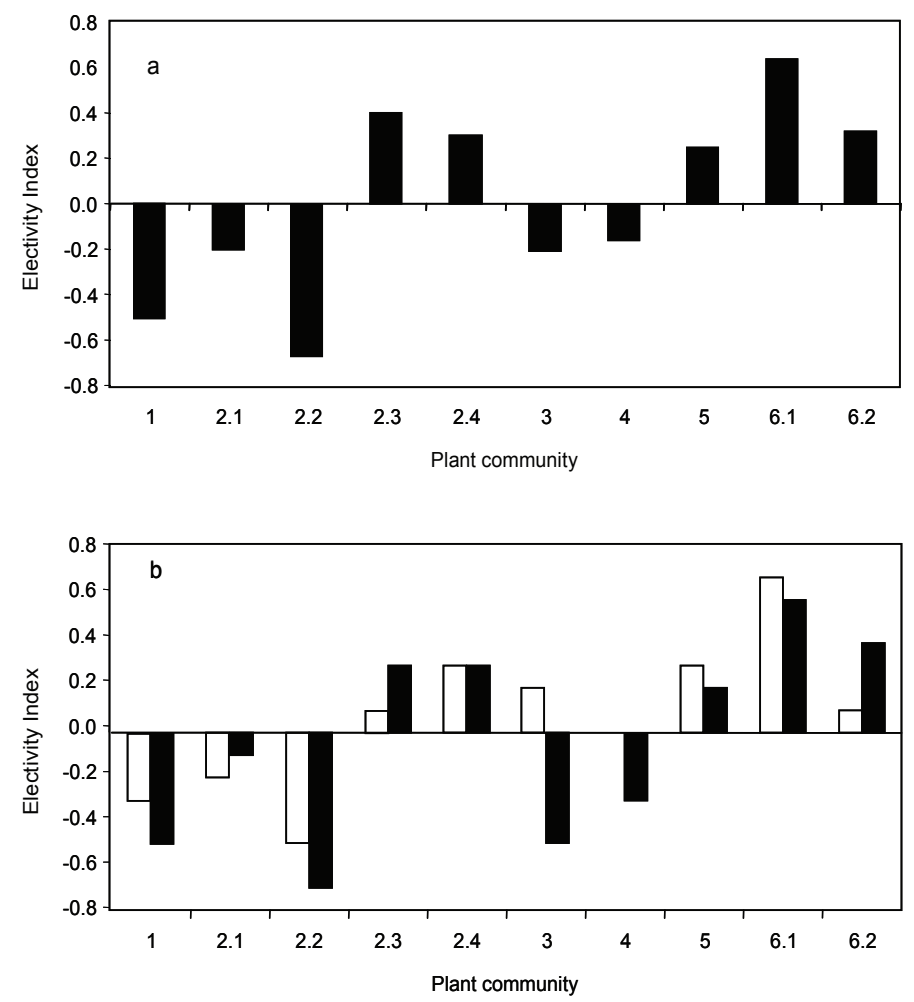

Fig. 5. The overall utilisation of plant communities in relation to their availability (a), expressed as an electivity index, together with seasonal preferences (b) for both the dry (open bars) and wet seasons (black bars). Plant community numbers are the same as those used in Fig. 4.

Combretum kraussii-Acacia ataxacantha Woodland (community 6.2), which covers a relatively large area $(55 \mathrm{ha}-10.6 \%$ of home range). Together, these findings suggest that although the baboons are most attracted to the Acacia woodland they prefer a specific sub-community within the woodland to the other sub-community and not Acacia woodland in general. The Faurea saligna-Cymbopogon validus Woodland (community 5 ) comprising 18.8 ha $(3.6 \%$ of home range) was slightly less preferred than the other woodland communities, but still a preferred community and utilised throughout the year. The next most preferred habitats consisted of grassland and shrubland (communities 2.3 and 2.4$)(42.5 \mathrm{ha}-8.1 \%$ of home range and 14.6 ha $-2.8 \%$ of home range respectively).
The least-preferred communities were the Hyperthelia dissoluta-Heteropogon contortus Grassland (community 1) and particularly, the Helichrysum wilmsii-Panicum natalense Grassland (community 2.2). The baboons mostly preferred only 140.2 ha $(26.9 \%)$ of their home range, showing the highest preference for the smallest community namely the Englerophytum magalismontanum-Acacia ataxacantha Woodland (community 6.1) which relates to food production and availability rather than plant community size. Qualitatively, the only observed seasonal effect was for community 3 (Englerophytum magalismontanum-Helichrysum kraussii Shrubland), which was avoided during the wet season and sought out during the dry (Fig 5b). 
Activity budgets. The allocation of time to each of the four behavioural states was determined as a percentage of the total activity budget. Overall, the baboons spent $62.3 \%$ of their time foraging, $24.3 \%$ moving and $10.2 \%$ resting. The remainder was allocated to social interaction. No seasonal differences were noted for foraging (wet: 62.5\%; dry $62.0 \%$ ), moving (wet: $23.1 \%$; dry: $26.3 \%$ ) or resting (wet: $10.6 \%$; dry: $9.6 \%$ ).

\section{Discussion}

Comparison with data from other chacma study sites (Stoltz \& Saayman 1970; Davidge 1978; Watson 1985; Gaynor 1995; Henzi \& Lycett 1995; Hill 1999) reveals that in their low densities, small mean group size, high investment in foraging and food search strategies that result in relatively short day ranges, the BCNR baboons bear the closest resemblance to the Drakensberg mountain population (population density $=2 \mathrm{ind} / \mathrm{km}^{2}$; mean group size $=21.4$; percentage time feeding $=68 \%$; mean day range $=4.6 \mathrm{~km}$ ) (Henzi \& Lycett 1995; Henzi et al. 1997). Together, these two populations are outliers in a subspecies that is, itself, characterised by small group sizes and high foraging demands (Henzi et al. 1999). The similarity is not surprising since both populations are subject to the direct and indirect effects of the elevation and relief of the Drakensberg escarpment, which result in high thermal demand and low food availability, at least in winter (Henzi et al. 1992).

Unlike the Natal Drakensberg population, though, the BCNR baboons forage in an environment that, by virtue of its lower latitude, is characterised by a much greater variability of habitat types within the home range (Henzi et al. 1992). Our results indicate that this corresponds to a greater variability in utilisation with a particular, but not surprising, preference for woodland, as this is likely to yield a better return for foraging effort (Hill \& Dunbar 2002). While we will consider this further elsewhere (Brown et al. 2005), there are two issues that can be pursued now.

The first is that the baboons clearly employ two different modes of engagement with their home range that is conditional on where they choose to forage on any one day. Successful foraging in grassland requires careful searching for cryptic food items and results in uniform, slow travel speeds and small day ranges

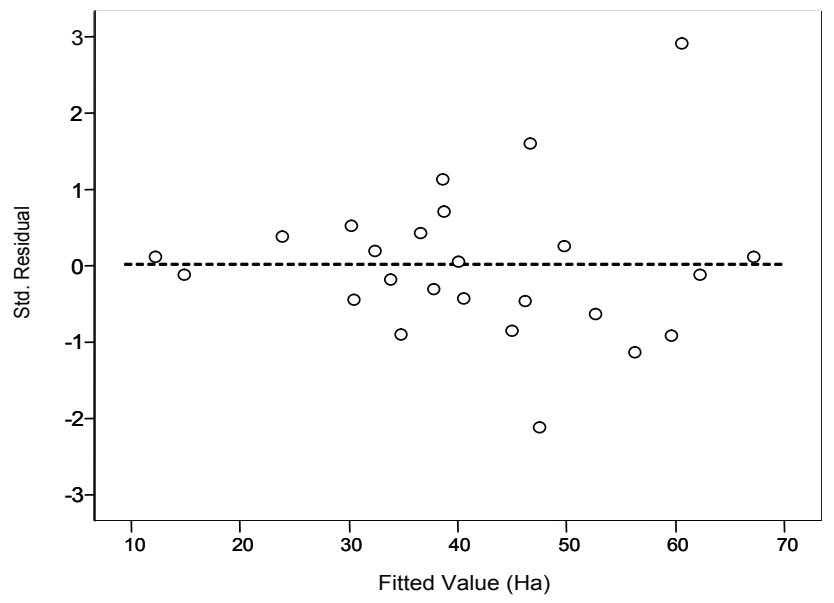

Fig. 6. The relationship between fitted values for area utilised (ha) and the standardised residuals for day journey length. 
(Henzi et al. 1992; Henzi et al. 1997), whereas utilisation of woodland generally involves greater variation in travel speed and distance travelled as animals move to a foraging area where they can subsequently obtain necessary resources in a small, circumscribed zone (Gaynor 1995). The general correlation we found between day-journey length and dayjourney area masks an additional relationship between the absolute size of the standardised residual and day-journey area that supports this (Fig. 6) $($ Rho $=0.69 ; n=25 ; p<0.01)$. Figure 6 indicates that longer day journeys, a characteristic of the dry season, were associated with the exploitation of either very small or very large areas. In our reading, and given the absence of seasonal effects in activity patterns, this suggests that the baboons were both moving and foraging consistently but slowly in small areas of grassland or moving rapidly over some distance (hence a large, positive residual) and then increasing their intake rate rapidly within a circumscribed area of relatively high food availability. The point is that the actual foraging zone of the troop - once travel is factored out - is always likely to be relatively small. Sample size precludes us investigating this but it remains a topic for further, more detailed analysis that considers exploitation in relation to the mix of habitat types encountered.

The second issue is that, despite the damage that they cause elsewhere, the study troop chose to avoid an easily accessible pine plantation. This avoidance, especially given the positive correlation between group size and number of group members $/ \mathrm{km}^{2}$ that suggests some local crowding, is telling and confirms Strum's point (1994) that raiding by baboons is not inevitable, nor is its occurrence predictable from gross local features. One or both of two possible reasons suggest themselves: either the baboons have available to them outside the plantation all the keystone resources they need or they target only forestry compartments of particular age/ size classes. Determining how these alternatives might interact requires comparative data and we have now expanded the study to include troops that do make use of plantations. Results will be reported elsewhere.
Lastly, one implication for conservation policy stems from the similarity of the BCNR baboon profile to that of the Drakensberg population. Long-term data from the Drakensberg reveals that recruitment to the baboon population is low, with female reproductive rate constrained by climate (Henzi \& Lycett 1995; Lycett et al. 1998). If, as seems likely, baboons of the Mpumalanga escarpment have comparably long inter-birth intervals, then the current forestry management practise of extirpation may reduce the long-term viability of baboon populations in protected areas.

\section{Acknowledgments}

We thank the NRF, Global Forest Products and Komatiland Forests for funding, and Mpumalanga Parks Board for permission to conduct the study.

\section{References}

AcOcKS, J.P.H. 1988. Veld types of South Africa. Memoirs of the botanical Survey of South Africa 57: 1-146.

Bezuidenhout, H. 1993. Syntaxonomy and synecology of the western Transvaal Grasslands. Ph.D. thesis, University of Pretoria, Pretoria.

BredenKAMP, G.J. 1982. 'n Plantekologiese studie van die Manyeleti-wildtuin. D.Sc. thesis. University of Pretoria, Pretoria.

Bredenkamp G.J., E. Granger \& N. van Rooyen. 1996. North-eastern Mountain Grassland. P. 46. In: Low, A.B. \& A.G. ReBelo (eds.). Vegetation of South Africa, Lesotho and Swaziland. Pretoria: Department of Environmental Affairs \& Tourism.

Bredenkamp, G.J., A.F., Joubert \& H. BezuidenHOUT. 1989. A reconnaissance survey of the vegetation of the plains in the PotchefstroomFochville-Parys Area. South African Journal of Botany 55: 199-206.

Bigalke, R.C. \& H.J. van Hensbergen. 1990. Baboon damage in plantation forestry in South Africa. South African Forestry Journal 152: 26-33.

Brown, L.R. \& G.J. BredenKamp. 1994. The phytosociology of southern section of the Borakalalo Nature Reserve, South Africa. Koedoe 37(2): 59-72.

Brown, L.R., H. Marais, S.P. Henzi \& L. BarRETT. 2005. Vegetation classification as the basis for baboon management in the Bourke's Luck 
Section of the Blyde Canyon Nature Reserve, Mpumalanga. Koedoe 48(2): 71-92.

Cowlishaw, G. \& R.I.M. Dunbar. 2000. Primate Conservation Biology. Cambridge: Cambridge University Press.

DAvidge, C. 1978. Activity patterns of chacma baboons (Papio ursinus) at Cape Point. Zooogica Africana 13: 143-155.

ECKHART, H.C. 1993. A synecological study of the vegetation of the north-eastern Orange Free State. M.Sc. thesis. University of Pretoria, Pretoria.

GAYNOR, D. 1995. Foraging and feeding behaviour of chacma baboons in a woodland habitat. Ph.D. thesis, University of Natal.

HENNEKENS, S.M. 1996. MEGATAB: A visual editor for phytosociological tables. Ulft: Giesen.

Henzi, S.P. \& J.E. LycetT. 1995. Population structure, dynamics and demography of mountain baboons. American Journal of Primatology 35: 155-163.

Henzi, S.P., R.W. Byrne \& A. Whiten. 1992. Patterns of movement by baboons in the Drakensberg Mountains: primary responses to the environment. International Journal of Primatology 13: 601-629.

Henzi, S.P., J.E. Lycett, A. Weingrill, R. Byrne \& A. Whiten. 1997. The effect of troop size on travel and foraging in mountain baboons. South African Journal of Science 93: 333-335.

Henzi, S.P., A. Weingrill \& L. Barrett. 1999. Male behaviour and the evolutionary ecology of chacma baboons. South African Journal of Science 95: 240-242.

HiLl, C.M. 2000. Conflict of interest between people and baboons: crop raiding in Uganda. International Journal of Primatology 21: 299-315.

Hill, M.O. 1979. TWINSPAN: A Fortran programme for arranging multivariate data in an ordered two-way table classification of individuals and attributes. New York: Cornell University.

HILL, R.A. 1999. Ecological and demographic determinants of time budgets in baboons: implications for cross-populational models of baboon sociobiology. $\mathrm{PhD}$ thesis, University of Liverpool.

HILL, R.A. \& R.I.M. DunBaR, 2002. Climatic determinants of diet and foraging behaviour in baboons. Evolutionary Anthropology 16: 579-593.

Kools, M.S., G.J. BredenKAmP \& G.K. Theron. 1990. Classification of the vegetation of the B land type in the north-western Orange Free State. South African Journal of Botany 56: 309-318.

Krebs, C.J. 1989. Ecological Methodology. New York: Harper and Row.

LyCETT, J.E., S.P. HeNZI \& L. BARRETT. 1998. Maternal investment in mountain baboons and the hypothesis of reduced care. Behavioral Ecology and Sociobiology 42:49-56.

MARAIS A.J. 2005. Resource utilisation of the chacma baboon in different vegetation types in northeastern mountain sour veld, Blyde Canyon Nature Reserve. M.Tech dissertation, University of South Africa.

Mueller-Dombois, D. \& H. Ellenburg. 1974. Aims and methods of vegetation ecology. New York: Wiley.

Stolz, L.P. \& G.S. SaAYMan. 1970. Ecology and behaviour of baboons in the northern Transvaal. Ann. Transvaal Museum 26, 99-143.

STRUM, S.C. 1994. Prospects for management of primate pests. Terre et Vie 49: 295-306.

Von dem Bussche, G.H. \& D. VAn der Zee. 1985. Damage by samango monkeys to pine trees in the northern Transvaal. South African Forage Journal 133: 43-48.

WATSON, L.H. 1985. The feeding ecology of chacma baboons and vervet monkeys in the HluhluweUmfolozi Reserve. M.Sc. thesis, University of Natal. 